\title{
The Weak Link in Veterans' Medical Care: An Expanded Role for Community Healthcare Providers
}

\section{Jeffrey L Brown ${ }^{1,2 *}$}

${ }^{1}$ Department of Pediatrics, New York Medical College, New York, USA

${ }^{2}$ Department of Psychiatry, Weill Cornell Medical College, New York, USA

\begin{abstract}
Eighty percent of military veterans receive most of their medical care from non-VA community providers. These providers do not identify them as veterans. The result is that service-related medical and psychological conditions are underdiagnosed, proper referrals are not made, and veterans do not receive services to which they are entitled. Community healthcare providers should know why and how to identify veterans and how to take a basic military health history.
\end{abstract}

Background: Many articles have appeared in the news that describe the problems that military veterans have when obtaining medical care at Veterans Administration (VA) facilities, but little attention has been focused on the quality of care that veterans receive from community providers. The reason for this is that most providers do not know which of their patients have served in the military.

Keywords: Health care; Community healthcare

\section{Current Status of the Problem}

\section{Misconception is at the core of this problem. Most community providers believe that}

- Few of my patients served in the military. False. The reason for this belief is that they don't ask patients one simple question, "Have you or someone close to you (spouse, child, parent, partner) ever served in the military [1]." In 2014, nine percent of adults ( 16 percent of males) above the age of 18 years have served in the military [2].

- If my patient has a medical problem related to past military service, they would tell me. False. Most veterans will not offer this information unless you ask them. That is why the American Academy of Nursing has started an initiative, "Have You Ever Served?" It encourages veterans to tell providers and practitioners to ask their patients about military service [3].

- I can usually spot a military veteran by his or her appearance. False. Most veterans look like your other patients. They are not all amputees, psychologically disturbed, or wearing an "I am a Veteran" cap.

- Most veterans receive their healthcare from the VA. False. In 2015,36 percent of veterans have signed up with the VA (3) but 80 percent of veterans receive most of their healthcare from community providers and hospitals. Most veterans who choose not to go to the VA have private health insurance, Medicare, or Medicaid [4].

- My specialty doesn't require me to know whether my patient has served. False. Almost 20 percent of active duty military personnel are women and one-third of active duty personnel have children under the age of 11 years $[5,6]$. It would be important to know whether your pregnant patient had an illness or toxic exposure that might affect the pregnancy. And pediatricians should want to know whether the child was affected by frequent moves, prolonged separation from parents, worries about a parent's well-being, at-home physically or psychologically unstable parents, etc.
- Past military service is unlikely to pertain to my patient's current problems. False. Many illnesses and psychological problems can cause immediate and delayed symptoms that go undiagnosed. A 50 year old patient with myalgia, arthralgia, fatigue, gastrointestinal problems might have Chronic Multisystem Disease (Gulf War Syndrome) that would not be included in a list of differential diagnoses. Vietnam veterans who make up one-third of the veterans' population were all exposed to dioxin in the defoliant known as "Agent Orange [6]." This can cause many forms of cancer, leukemia, type ii diabetes, ischemic heart disease, Parkinson's disease, peripheral neuropathy, and many other ailments [7].

- If a patient has PTSD (Post Traumatic Stress Disorder) it will be obvious. False. The presentation of PTSD and Traumatic Brain Injury can be very variable. Both are often misdiagnosed as anxiety disorder, problems of cognition, substance abuse, and other conditions. In addition, patients with psychological disorders may present with physical rather than psychological complaints. Many older veterans do not realize that their psychological symptoms are caused by Late Onset PTSD. They blame their symptoms on retirement, financial worries, or feeling physically vulnerable as they age. They often do not realize when their symptoms are caused by a delayed response to combat stress that occurred decades earlier [8].

- If a patient does have a service-related disability, there is not much I can do to help him or her. False. Your patient already trusts you and your advice. Once you have identified a problem that may relate to military service, you can learn more about it

*Corresponding author: Jeffrey L Brown, Professor of Pediatrics, New York Medical College, 10 Walnut Court, White Plains NY 10605, USA, Tel: 914 5525013; E-mail: JLBrown100@msn.com

Received: July 17, 2016; Accepted: July 23, 2016; Published: July 30, 2016

Citation: Brown JL (2016) The Weak Link in Veterans' Medical Care: An Expanded Role for Community Healthcare Providers. J Pat Care 2: 115. doi: 10.4172/25734598.1000115

Copyright: (c) 2016 Brown JL. This is an open-access article distributed under the terms of the Creative Commons Attribution License, which permits unrestricted use, distribution, and reproduction in any medium, provided the original author and source are credited. 
by going to the va.gov or military.com websites. You can also refer the patients to your state's local veterans' counselor who can mentor them about available benefits. Your patients may be eligible for free medicines and other services like physical or speech therapy that may not be covered by private insurance.

\section{Clinicians' Concerns}

\section{Once they are aware of the problem, community providers frequently have the following concerns}

- I do not know how to take a military health history and which questions to ask. The basic information that should be documented is similar to the kinds of questions you would ask if you learned that your patient had previously been in a hazardous occupation or was exposed to a hazardous substance like asbestos [9].

- WHEN were you in the military? WHERE were you stationed? WHAT did you do (job description) while you were there?

- Have you ever been treated for any illnesses or injuries that were related to your time in the military? (Some of these may be from accidents or other non-combat related activities).

- Do you believe that you currently have any medical or psychological problems that may have been caused by something related to your time in the military?

- Have you ever contacted or been treated at the VA for any medical or psychological problems?

Are there any questions I should not ask? If you feel uncertain about discussing military service with your patient, you can ask for permission first. "I would like to ask you some questions about your time in the military. It may be helpful to have this information in your chart. Is it okay if I ask you these questions? Is there anything specific that you would like to share with me?" You should NOT ask, "Have you ever killed anyone?" That kind of question should be reserved for someone who deals with veterans regularly or when it is pertinent to a longer term relationship.

If a patient has not served in combat, does that mean that he or she is immune from service-related problems? No. There are many military jobs that are intrinsically dangerous. Military personnel are dealing with munitions, toxins, heavy machinery, loud noise, and many other potential hazards. In addition, it is not unusual for service personnel to suffer from non-combat psychological problems. Just being in a hostile area is stressful whether or not you are in the direct line of fire.

Where does this military information belong in the medical record? There are a number of groups working to have pertinent military history questions become part of all electronic health records. Until that time, this information belongs in three places: It belongs in the demographic information together with insurance information (underinsured patients may be eligible to apply for benefits), in the social history (if the patient or family members have been affected by their service) and in the past medical history as pertinent risk factors for present or future illnesses.

If I want to explore this topic more fully, where should I look? The va.gov and military.com websites are good places to start. But a simple search will bring up very valuable information that can tell you the most likely medical and psychological conditions associated with military deployments to specific regions like Afghanistan, Iraq, Vietnam, etc.

If I make the extra effort to identify patients who have served in the military, will that make me a better healthcare professional? Absolutely. Military service can be the sentinel experience in an individual's life and it is necessary to identify risk factors for any medical or psychological illness. (Does your patient smoke, abuse drugs or alcohol, live in an unsafe environment, etc..?) The impact of past military service can affect present, past and future medical and psychological well-being, so it is important to incorporate it into your knowledge about the patient. Your professional obligation extends past saying, "Thank you for your service."

\section{References}

1. Brown JL (2012) The unasked question. JAMA 308: 1869-1870.

2. National Center for Veterans Statistics and Analysis. Quick facts.

3. American Academy of Nursing. Have you ever served in the military?

4. Strategic Analysis Services, 2016 Survey of veteran enrollees health and use of healthcare.

5. Department of Defense. National womens history.

6. http://historyinpieces.com/research/us-military-personnel-1954-2014

7. US Department of Veterans Affairs. Public health.

8. National Center for PTSD, US Department of Veterans Affairs. PTSD.

9. Office of Academic Affiliations, US Department of Veterans Affairs. Pocket card for clinicians. 